\title{
Applied Horticultural Biotechnology for the Mitigation of Indoor Air Pollution
}

\author{
Fraser R. Torpy ${ }^{1 *}$, Thomas Pettit ${ }^{1}$, and Peter J. Irga ${ }^{2}$ \\ ${ }^{1}$ Plants and Environmental Quality Research Group, Faculty of Science, University of Technology Sydney \\ ${ }^{2}$ Plants and Environmental Quality Research Group, School of Civil and Environmental Engineering, Faculty of Engineering and \\ Information Technology, University of Technology Sydney
}

\begin{abstract}
Exposure to indoor air pollution is an emerging world-wide problem, with growing evidence that it is a major cause of morbidity worldwide. Whilst most indoor air pollutants are of outdoor origin, these combine with a range of indoor sourced pollutants that may lead to high pollutant levels indoors. The pollutants of greatest concern are volatile organic compounds (VOCs) and particulate matter (PM), both of which are associated with a range of serious health problems. Whilst current buildings usually use ventilation with outdoor air to remove these pollutants, botanical systems are gaining recognition as an effective alternative. Whilst many years research has shown that traditional potted plants and their substrates are capable of removing VOCs effectively, they are inefficient at removing PM, and are limited in their pollutant removal rates by the need for pollutants to diffuse to the active pollutant removal components of these systems. Active botanical biofiltration, using green wall systems combined with mechanical fans to increase pollutant exposure to the plants and substrate, show greatly increased rates of pollutant removal for both $\mathrm{VOCS}, \mathrm{PM}$ and also carbon dioxide $\left(\mathrm{CO}_{2}\right)$. A developing body of research indicates that these systems can outperform existing technologies for indoor air pollutant removal, although further research is required before their use will become widespread. Whilst it is known that plant species selection and substrate characteristics can affect the performance of active botanical systems, optimal characteristics are yet to be identified. Once this research has been completed, it is proposed that active botanical biofiltration will provide a cheap and low energy use alternative to mechanical ventilations systems for the maintenance of indoor environmental quality.
\end{abstract}

Keywords: active green walls, indoor air quality, phytoremediation, potted plants, volatile organic compounds

\section{Introduction}

\section{Urban air pollution; sources and concerns}

Air pollution has long been recognised as a major cause of morbidity, especially in urban populations. As modern people spend an increasing proportion of their lives indoors (Klepeis et al., 2001), human exposure to many air pollutants is far greater indoors than occurs in the outdoor environment (Molloy et al., 2012). Whilst indoor air pollutant concentrations are generally very low, lifetime exposure is known to lead to adverse health effects (Wolkoff, 2013). As building 
fresh air exchange rates are continually reduced in an effort to improve energy efficiency, and populations worldwide shift towards greater urbanisation (World Health Organization, 2016), this situation is increasing in significance. In the United States, it has been estimated that 800,000-1.2 million buildings may be associated with building-related illnesses, exposing 30-70 million workers to unhealthy working conditions (Fiedler et al., 2005).

The primary source of most indoor air pollution is through outdoor pollutants entering a building. These pollutants are then augmented by indoor-generated pollutants. These include carbon dioxide from occupant respiration, dust and other forms of particulate matter (PM) depending on the nature and intensity of occupant activity, such as cooking, solid fuel heating and cigarette smoking (Buonanno et al., 2009), and a range of volatile organic compounds (VOCs), which are organic materials that are off-gassed from most synthetic materials, solvents and cleaning products (Torpy et al., 2015). Irrespective of the source of indoor air pollutants, contemporary building ventilation rates are generally insufficient to remove them effectively, thus they accumulate in the indoor space (Weschler, 2009), leading to concentrations of some compounds that are 2-4 times higher than those of the same pollutants in outdoor air (Jafari et al., 2015). Building energy use has become a growing concern since the 1970's (Seppänen et al., 2006). In an effort to reduce thermal exchange with outdoor air, The American Society of Heating, Refrigerating and Air-Conditioning Engineers (ASHRAE) have several times adjusted their standard for building ventilation rates, reducing the rate at which indoor air should be replaced with outdoor air (Burroughs and Hansen, 2004). Concurrently, there has been a growth in the use of materials that emit gaseous compounds, in particular the development of a diverse range of plastics (Jafari et al., 2015). Whilst recent initiatives to utilise safer materials has led to reductions in off gassed VOCs along with a general ambivalence in the building industry to the low levels of pollutants often found indoors (which are generally in the parts per billion range), there is a growing body of evidence documenting pollutant-associated symptoms even in buildings that were previously considered 'clean' (Colbeck and Nasir, 2010). This situation is now at a stage where indoor air pollution has become a major consideration in public health, and is now listed as a major environmental health risk by the World Health Organization (World Health Organization, 2010). Indoor air pollution health-associated costs for developed countries is likely to be just under US\$90 trillion (Hutton, 2013).

\section{Indoor air pollutants}

Whilst a broad range of air pollutants have been detected in indoor environments, indoor exposure to those such as nitrogen and sulfur oxides, ozone and radon are of limited importance to human health, except in specific circumstances. Quantitatively, the indoor air pollutants of greatest concern are VOCs, $\mathrm{CO}_{2}$ and PM.

\section{Volatile organic compounds}

The general class of air pollutants described as VOCs includes a broad range of carbon-containing, low boiling-point compounds that are gaseous at room temperature. Whilst high levels of many VOCs are known to be highly toxic, leading to hematotoxic, neurotoxic, leukemogenic and carcinogenic symptoms (Vaughan et al., 1986; Wallace, 2001), at levels that are too low to be perceived by humans $(<200 \mathrm{ppb})$, mixtures of VOCs are generally accepted to cause significant negative health outcomes, often described as symptoms of 'sick-building-syndrome', such as lethargy, mucous membrane and respiratory effects (Jaakola et al., 2007). In any building, 50-300 different VOCs are likely to be present (Bernstein et al., 2008).

\section{Carbon dioxide}

Indoor $\mathrm{CO}_{2}$ is mainly sourced from human respiration. Whilst $\mathrm{CO}_{2}$ is not toxic, at high indoor levels it can act as a 
narcotic, and lead to dry eyes, sore throat, nose congestion, sneezing, along with shortness of breath, coughing and headaches (Erdmann and Apte, 2004). There is a well-documented association between increased $\mathrm{CO}_{2}$ levels and poor health outcomes, academic performance and work productivity in building occupants (Milton et al., 2000; Bakó-Biró et al., 2004; Erdmann and Apte, 2004; Seppänen and Fisk, 2004; Seppänen et al., 2006; Shaughnessy et al., 2006). The means by which $\mathrm{CO}_{2}$ is controlled in buildings is normally through ventilation with outdoor air by the ventilation component of heating, ventilation and air conditioning (HVAC) systems: If the ventilation rate is insufficient, $\mathrm{CO}_{2}$ accumulation will occur (Redlich et al., 1997).

\section{Suspended particulate matter}

Indoor PM is sourced through the transfer of outdoor air pollution through ventilation systems or building openings, along with the emission or re-suspension of indoor sourced particles from activities such as smoking, cooking and cleaning (Morawska et al., 2003). Fine PM with an aerodynamic diameter of $<2.5 \mathrm{~mm}\left(\mathrm{PM}_{2.5}\right)$ is of particular concern, as these finer particles can penetrate more deeply into the respiratory system, and thus have greater health effects than coarser particles (Xing et al., 2016). The association between elevated PM levels and adverse health effects is becoming increasingly prominent, as is the documented presence of problematic PM levels in some indoor environments (Wyzga et al., 2015; Maji et al., 2017; Tunno et al., 2015). Currently, clear associations between PM exposure and health symptoms relate to cardiovascular, respiratory and venous thromboembolic disease (Bari et al., 2014).

Urban fine PM is mainly composed of black carbon associated with harmful hydrocarbons, resulting from diesel engine use (Rohr and Wyzga, 2012). Thus, most harmful indoor PM is of outdoor origin. Whilst most modern buildings utilise filters in their HVAC systems, filtration efficiency for fine and ultra-fine PM is generally under 20\% (Riley et al., 2002), with more efficient filtration met with significantly increased energy requirements (Quang et al., 2013).

\section{Air quality bioremediation}

It is clear that indoor air quality is a growing concern worldwide. Whilst there are a range of physiochemical methods available for the mitigation of these pollutants (eg. see Torpy et al., 2015), all of these methods are expensive, limited in the number of pollutants they can remove, and require energy to run. Utilising biological processes for air pollutant removal thus has considerable potential if cost-effective and safe systems with adequate efficiency can be developed (Kim et al., 2018).

The current article thus describes the major stages in the development of botanical phytoremediation systems that have allowed them to become practical alternatives for the maintenance of healthy indoor environments.

\section{Botanical systems can improve air quality}

It was initially found that plants could be of value in maintaining air quality in a sealed environment during research aimed at developing Biological Life Support Systems (BLSS) for use in space craft and space stations (André and Chagvardieff, 1997; Salisbury et al., 1997). Whilst the primary use of plants in these systems was for food supply, it was also found that the crop plants could contribute substantial $\mathrm{CO}_{2}$ and VOC removal (Wheeler et al., 1996), the latter being of particular concern after the identification of high VOC levels in NASA trials (Wolverton et al., 1984). Subsequently, NASA conducted a range of studies that showed that many species of indoor plant were highly effective removing a range of VOCs from sealed chamber atmospheres (Wolverton et al., 1984; Wolverton and Wolverton, 1993). These proofof-concept trials provided clear evidence that plants could play a role in the removal of air pollutants from sealed 
atmospheres. The generalisation of these effects to the built environment began with the study by Wood et al. (2002), who recognised that contemporary, highly sealed buildings were not dissimilar to the sealed spacecraft tested by NASA. Wood et al. (2002) determined that repeated doses of high-level VOCs could be removed with a single potted plant system, and this activity could be sustained indefinitely, with accelerating rates of removal on successive doses (Figure 1). VOC removal rates in these chamber studies were very high, with a $10 \mathrm{ppm}$ dose completely removed from the chamber atmospheres within $24 \mathrm{~h}$, once the system had been 'induced' for benzene removal with an initial $10 \mathrm{ppm}$ dose. The most significant finding of Wood et al. (2002), however, was the identification that VOC removal, at least for the hydrophobic VOC benzene, was likely to be largely a bacterial, rather than a plant mediated process. This was determined from the finding that the removal of the plant leaving only the potting mix did not have a major effect on VOC removal, and that plants in hydroponic media, with a substantially lower bacterial density to potting mix, had considerably reduced VOC removal rates (Figure 1). In contrast to these findings, plants may play a major role in the removal of hydrophilic VOCs, such as formaldehyde, the removal of which is clearly through a different but complementary phytoremediation pathway (Kim et al., 2008, 2010).

\section{The development of static botanical systems}

The determination that VOC removal by potted plants was largely a microbial process led to the idea that if the bacteria responsible for the process could be identified and their growth accelerated, VOC removal could be enhanced. Torpy et al. (2013) thus used carbon source utilization profiles (community level physiological profiling), through the use of Biolog MicroPlates; (eg. Grayston and Prescott, 2005) to identify carbon sources that favoured the growth of VOC-degrading bacterial, and using them to 'biostimulate' the substrate of potted plants. Whilst his process was successful, achieving a $\sim 15 \%$ increase in VOC removal rates (Figure 2), this work was not developed further, and thus has not been used in practice.

Irga et al. (2013) expanded on this research, examining hydroculture systems that were specifically designed for VOC

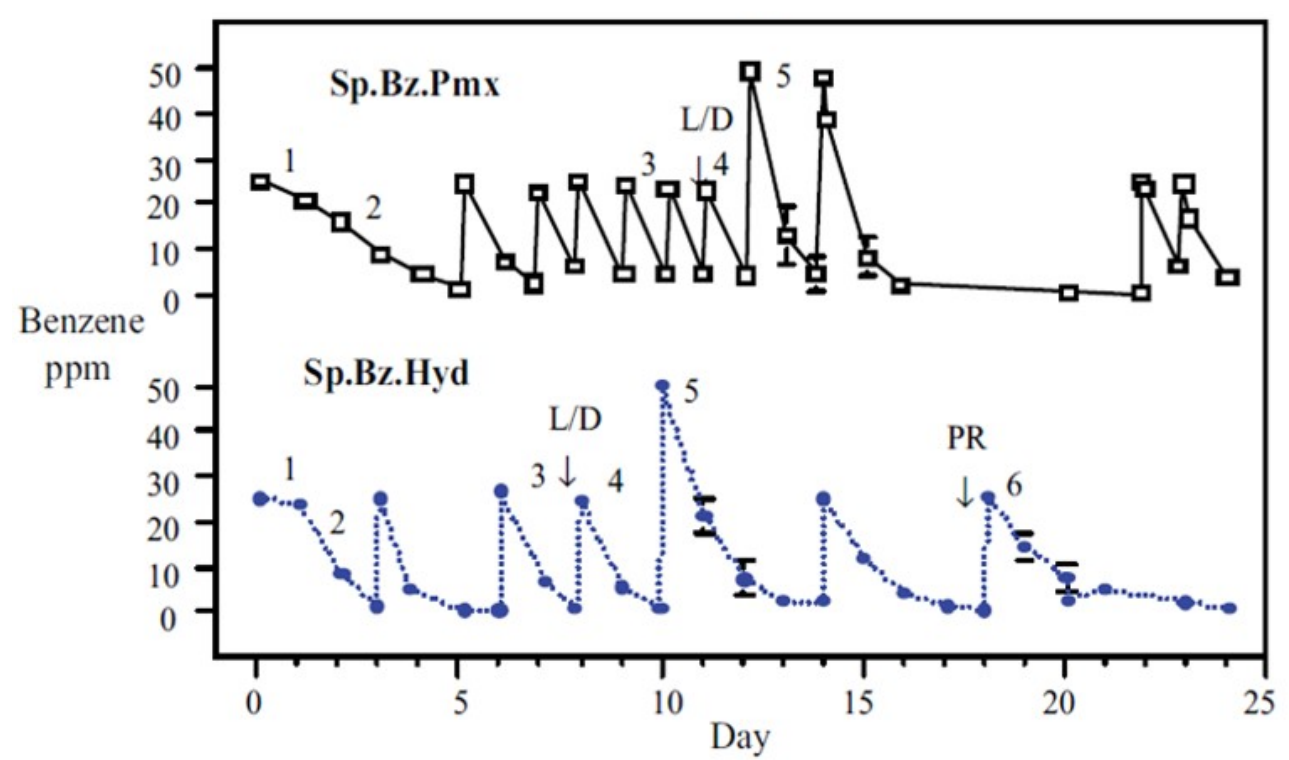

Figure 1. Repeated doses of benzene from Spathiphyllum plants in potting mix (above) and hydroponic media (below). Reprinted from "Potted-plant/growth media interactions and capacities in removal of volatiles from indoor air", by R.A. Wood et al., 2002, The Journal of Horticultural Science and Biotechnology, 77(1), pp. 120-129. 
removal. As was the case in Wood et al. (2002), whilst effective air pollutant removal systems were developed, they did not match the effectiveness of organic potting mixes (Figure 3), reinforcing the theory that a complex bacterial community is required for effective VOC remediation.

With the discovery that potted indoor plants could prove effective in mediating VOC levels in occupied buildings (see following section), work then progressed to study whether indoor plants could be effective for $\mathrm{CO}_{2}$ removal, and in doing so, reduce building ventilation energy requirements. Thus Torpy et al. (2014) tested the static chamber $\mathrm{CO}_{2}$ removal rate of a range of indoor plants at a range of light levels. This research found that normal indoor light levels were insufficient to support adequate photosynthesis to perform a useful $\mathrm{CO}_{2}$ removal role, however with additional light, significant photosynthetic $\mathrm{CO}_{2}$ removal occurred (Figure 4). Whilst promising pollutant removal was recorded in these chamber

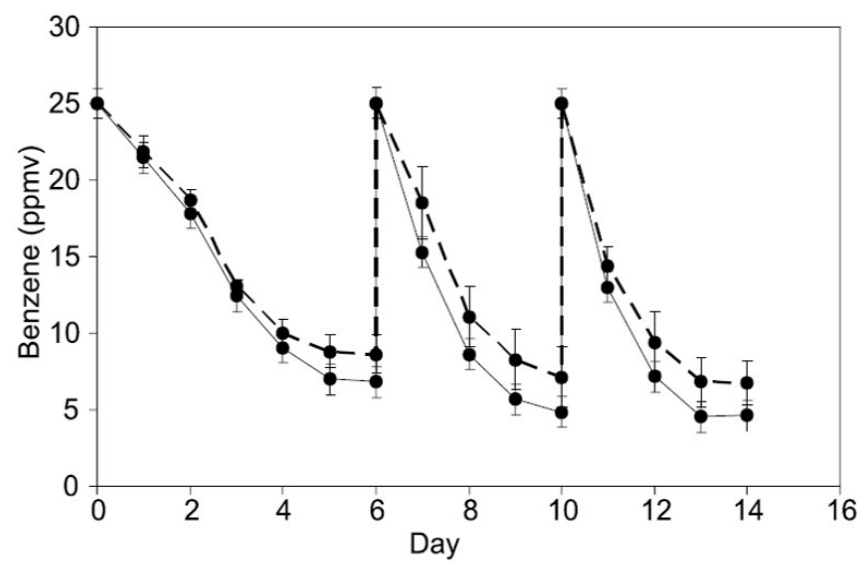

Figure 2. Rates of benzene removal for non-biostimulated and biostimulated potted plants. A 25 ppm benzene dose was applied to the experimental chambers at days 0, 6 and 10. Solid line = biostimulated plants; dashed line = non-biostimulated plants. (Means \pm SEM. $n=11$ non-biostimulated plants; $n=4$ biostimulated plants.) Reprinted from "Characterization and biostimulation of benzene biodegradation in the potting-mix of indoor plants”, by F.R. Torpy et al., 2013, Journal of Applied Horticulture, 15(1), pp. 10-15.

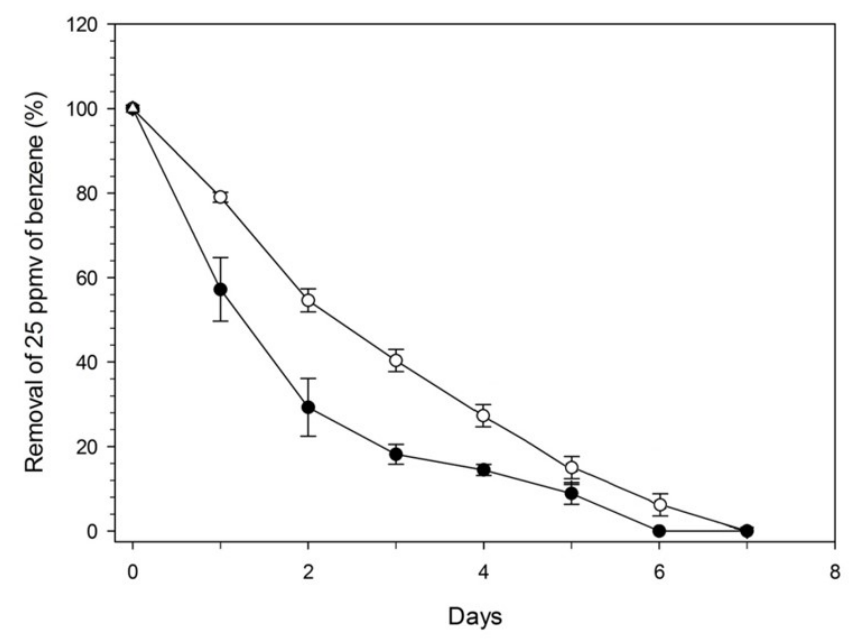

Figure 3. Removal of $25 \mathrm{ppm}$ benzene from sealed chambers with planted systems: Open circles = hydroculture media; closed circles = potting mix (Means $\pm \mathrm{SE}, n=4$ ). Reprinted from "Can hydroculture be used to enhance the performance of indoor plants for the removal of air pollutants?”, by P.J. Irga et al., 2013, Atmospheric Environment, 77, pp. 267-271. 
studies, to have a meaningful effect on indoor $\mathrm{CO}_{2}$ levels in full-sized buildings it was estimated that a very large number of plants would be required, along with very high indoor light additions (Torpy et al., 2014).

\section{In situ effectiveness}

Whilst effective pollutant removal rates have been demonstrated in trials using small $\left(<1 \mathrm{~m}^{3}\right)$ sealed chambers, it is not fully clear whether these findings can be generalised to full scale buildings (eg. Llewellyn and Dixon, 2011). Of the few in situ studies performed, Wood et al. (2006) compared VOC levels in a number of university offices with none, 3 or 6 large (300 mm diameter) indoor plants over two, nine-week periods. They found that, whilst zero-plant offices had considerably higher VOC levels than nearby outdoor areas as expected, offices with either 3 or 6 plants had VOC concentrations similar to outdoor levels, with total VOC concentrations consistently below 100 parts per billion (Figure 5). Whilst $\mathrm{CO}_{2}$ levels were also slightly lower in offices containing plants, the magnitude of the effect was insufficient to be of real value, with mechanical ventilation still necessary to maintain $\mathrm{CO}_{2}$ at habitable levels.

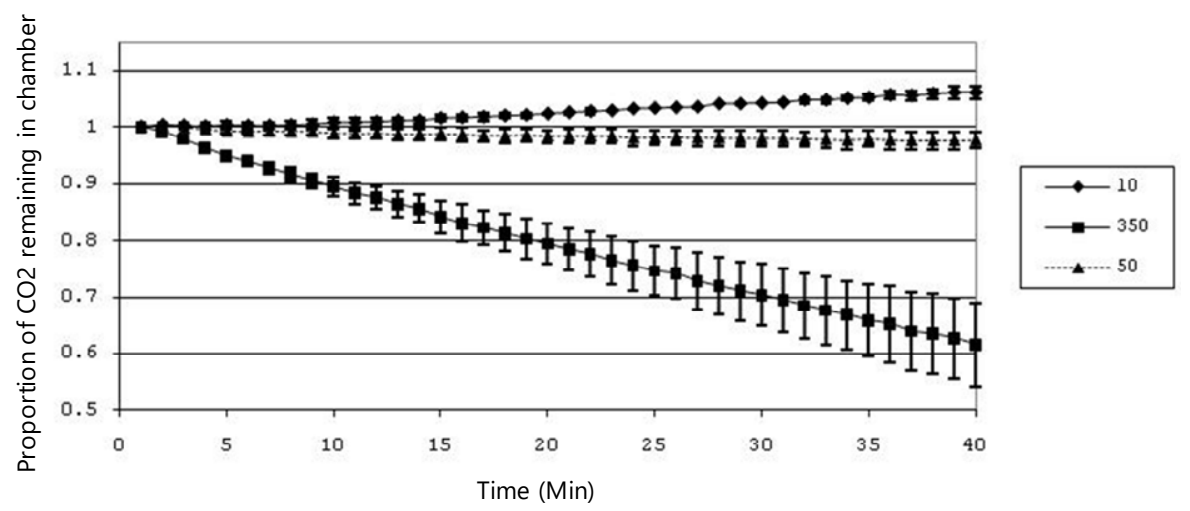

Figure 4. Changes in test-chamber $\mathrm{CO}_{2}$ concentrations in glasshouse acclimated Howea fosteriana, sampled at 3 light levels: 10, $50 \& 350 \mu \mathrm{mol} \mathrm{m} \mathrm{m}^{-1}$. (Means $\pm \mathrm{SE} ; n=8$ ). Adapted from "Profiling indoor plants for the amelioration of high $\mathrm{CO}_{2}$ concentrations”, by F.R. Torpy et al., 2014, Urban Forestry \& Urban Greening, 13(2), pp. 227-233.

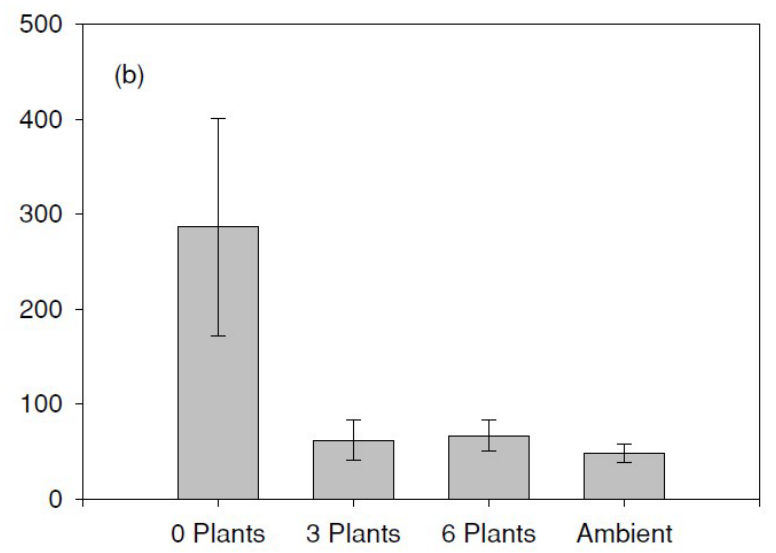

Figure 5. VOC levels in university offices with 0,3 or 6 plants, and proximal outdoor areas. Values are means $\pm \mathrm{SE}, n=$ 18. Reprinted from "The potted-plant microcosm substantially reduces indoor air VOC pollution: I. Office field-study”, by R.A. Wood et al., 2006, Water, Air, and Soil Pollution, 175(1), pp. 163-180. 


\section{Active phytoremediation}

The primary limitations of potted plant systems for practical pollutant management indoors are the rate at which pollutants can migrate to the active system components (ie. substrate for VOCs, plant leaves for $\mathrm{CO}_{2}$ ), and the large numbers of plants required for meaningful air cleaning (Waring, 2016). Both of these problems can be overcome with active biofilter / green wall technology, which is the most recent development in indoor botanical air cleaning. Active biofilters use some form of mechanical system to increase the rate that polluted air is exposed to the plant substrate and plants themselves. Almost all of the systems developed use electric fans for this purpose (eg. see Figures 7 and 8 ). The use of active systems was first postulated in the previously described NASA studies, where Wolverton et al. (1989) suggested that the addition of a small air pump to a potted plant could increase the rate at which pollutants could be transferred from the atmosphere to the plant substrate, and thus bioremediated.

The first research to test active systems was Darlington et al. (2001), who found that whilst specific VOC removal rates were highest with slower airflow rates (and thus longer pollutant residence time in the substrate), the greatest volumetric air cleaning rates were achieved with high airflow rates. These findings were corroborated by Delhoménie and Heitz (2003). As predicted, the systems tested by these authors had very high VOC removal rates relative to the floor areas their systems occupied, indicating the potential of active vertical garden systems for effective air cleaning. Wang and Zhang (2011) developed a 'dynamic biological air filtration system' specifically targeted at air quality phytoremediation. This system, along with the biological components involved in botanical air cleaning systems, included activated carbon in the substrate, leading to very high VOC removal efficiencies for toluene and formaldehyde ( $91.7 \%$ and $98.7 \%$ respectively). Recent work by Torpy et al. (2018a,b) using commercially-available active green wall systems has further documented their efficacy at VOC removal for a range of diverse VOCs.

Regarding $\mathrm{CO}_{2}$ removal, Su and Liang (2015) showed that a $5.72 \mathrm{~m}^{2}$ indoor plant wall could reduce the $\mathrm{CO}_{2}$ concen-

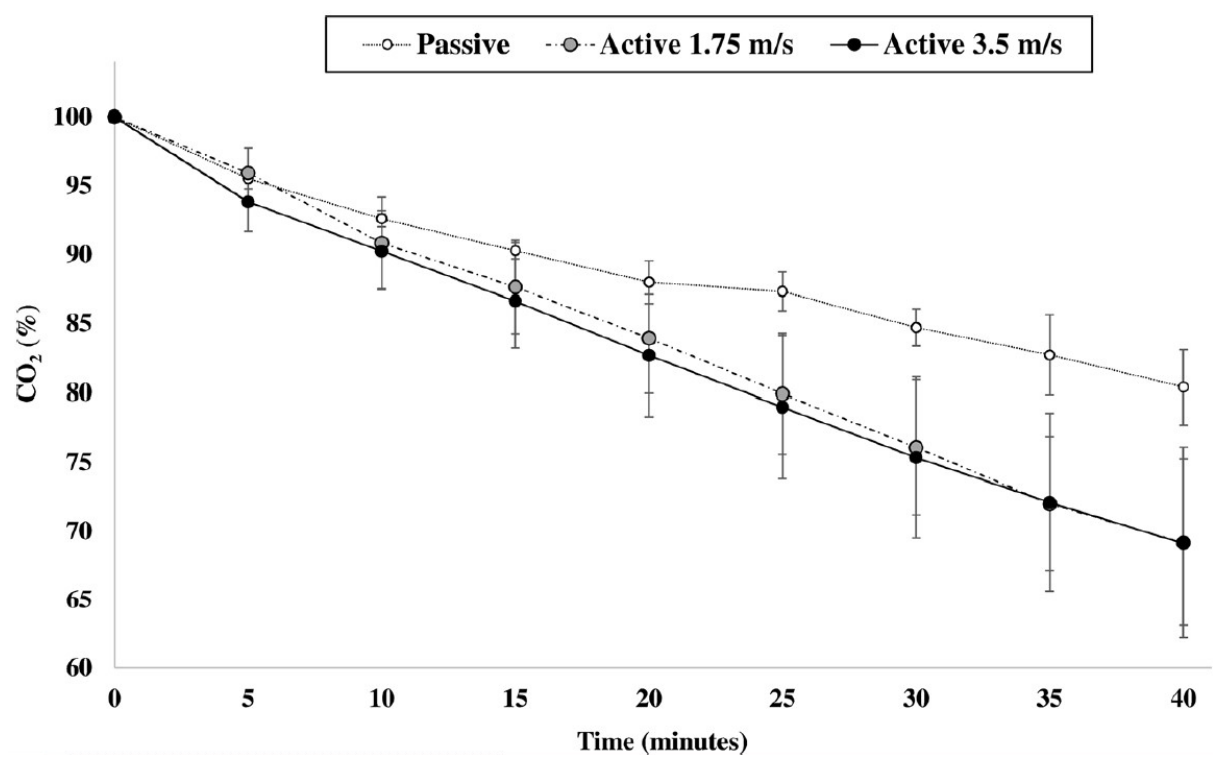

Figure 6. Chamber trials of $\mathrm{CO}_{2}$ draw down (as \% of a starting concentration of $\sim 1000 \mathrm{ppmv}$ ) for Chlorophytum comosum active green walls at $100 \mu \mathrm{mol} \mathrm{m} \mathrm{m}^{-2} \cdot \mathrm{s}^{-1}$ photon flux density, with active ventilation off, and running at two speeds. Data are means $\pm \mathrm{SE}, n=3$. Reprinted from "Green wall technology for the phytoremediation of indoor air: a system for the reduction of high $\mathrm{CO}_{2}$ concentrations, by F.R. Torpy et al., 2017, Air Quality, Atmosphere \& Health, 10(5), pp. 575-585. 


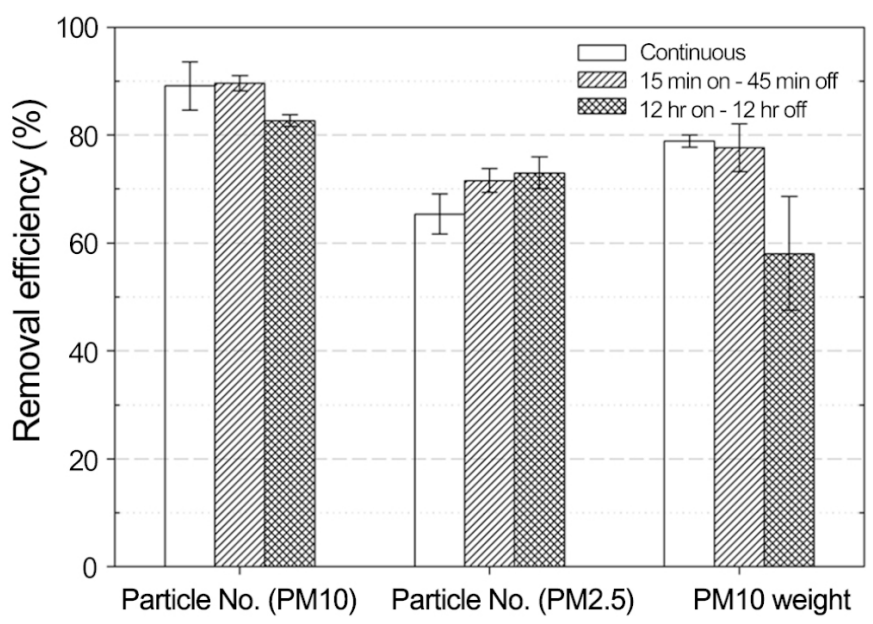

Figure 7. Removal efficiency of particle numbers of fine dust $(2-10 \mu \mathrm{m})$ and ultra-fine dust $(0.3-2 \mu \mathrm{m})$, and of PM10 weight $\left(\mu \mathrm{g} . \mathrm{m}^{-3}\right)$ in a wall-type botanical biofilter, depending on three humidifying cycles. Error bars present SE. Reprinted from "Stabilization of soil moisture and improvement of indoor air quality by a plant-biofilter integration system, by C.H. Lee et al., 2015, Korean Journal of Horticultural Science and Technology, 33(5), pp. 751-762.

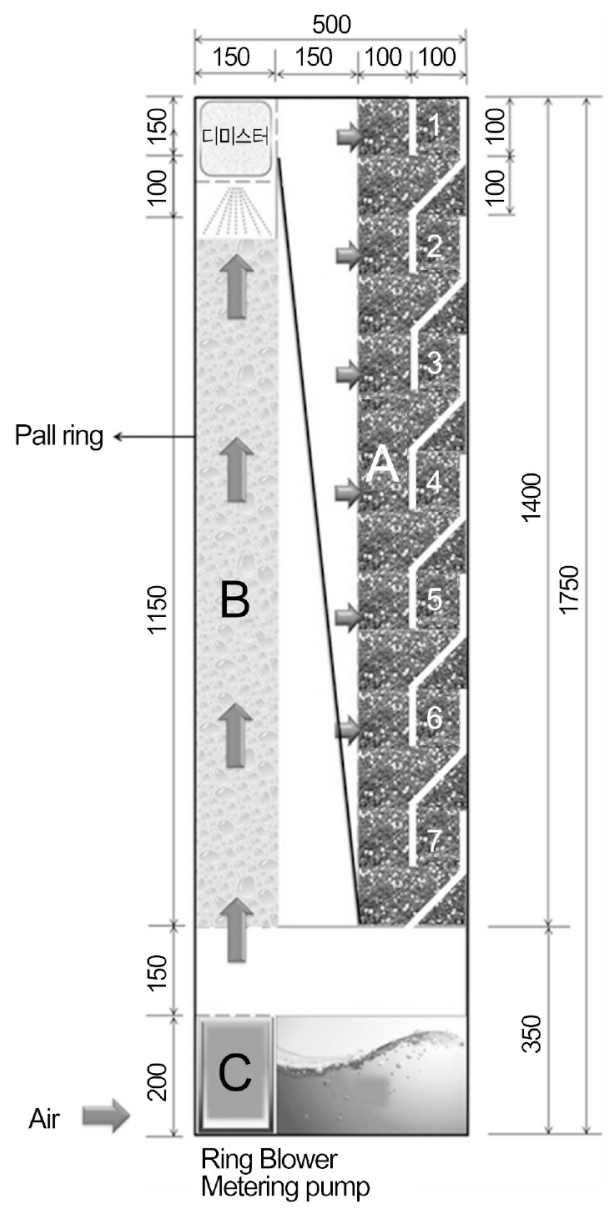

Figure 8. Active biofilter with humidifying system used by Lee et al. (2015). Reprinted from "Stabilization of soil moisture and improvement of indoor air quality by a plant-biofilter integration system, by C.H. Lee et al., 2015, Korean Journal of Horticultural Science and Technology, 33(5), pp. 751-762. 
tration of a small room from 2000 to 800 ppm within an hour. Torpy et al. (2017) showed that, whilst passive green walls (i.e. those without any means of active airflow through the substrate) were capable of considerable $\mathrm{CO}_{2}$ removal, adding airflow through the substrate significantly increased the $\mathrm{CO}_{2}$ removal rates (Figure 6). Whilst the authors (Torpy et al. 2017) did not examine this phenomenon explicitly, it was suggested that the volumetric increase in atmospheric exposure to the plant foliage may have led to this increase in performance.

The value of these findings aside, it is likely that the major barrier to effective active green wall $\mathrm{CO}_{2}$ mitigation in practical applications will relate to light availability, as providing the high light levels required for adequate photosynthetic activity, whilst maintaining habitable indoor workspaces, may prove challenging (Torpy et al. 2017).

\section{The performance development of active botanical biofilters}

Whilst active botanical biofiltration has clear potential for practical removal of $\mathrm{VOCs}$ and $\mathrm{CO}_{2}$ under some circumstances, the use of accelerated airflow through biological material offers the potential for the generation of hazardous mould spores. The research performed by Irga et al. (2017), however, demonstrated that, as the plant growth substrate in active green walls functionally acts as a filtration matrix, active biofilters do not increase the fungal spore load in buildings, and may even reduce them in some cases.

This filtration capacity was recognised by several authors as having the potential to remove particulate matter, along with VOCs and $\mathrm{CO}_{2}$ from the air. Whilst it is well known that outdoor plants can accumulate PM (Sæbø et al., 2012); indoor plant PM removal has been comparatively poorly studied. Stapleton and Ruiz-Rudolph (2016) showed that the presence of a range of indoor plants was associated with fine PM removal in a static chamber study, with leaf surface area the main determinant of PM reduction. A subsequent study by Weerakkody et al. (2017) also noted that leaf area was the main plant characteristic that affected plant PM deposition.

The first attempt to test PM removal by an active green wall system was by Lee et al. (2015), with their system removing 83-90\% of $\mathrm{PM}_{10}$ (particles with an aerodynamic diameter of $<10 \mu \mathrm{m}$ ), and 65-73\% removal efficiency for $\mathrm{PM}_{2.5}$ (Figure 7), with efficacy depending on a 'humidifying' cycle, whereby water was atomised into the polluted airstream before entry into the biofilter substrate (Figure 8).

Irga et al. (2017) developed these trials further, using a commercial system (The Breathing Wall) developed by Australian company Junglefy Pty. Ltd. In this system, polluted air is pumped into an aperture in the rear face of a polyethylene case, where it enters a plenum before distribution across the rear face of the plant growth substrate (made from coconut husks), before returning to ambient through the plant foliage (Irga et al., 2017; Figure 9). To match contemporary particulate filter testing methods, Irga et al. (2017) tested the single pass removal efficiency (SPRE) of their green wall system, whereby the ability of the system to reduce a single pass of polluted air through the matrix was documented, using a flow-through test system (Figure 10).

The results of these trials were promising, with $\sim 50-80 \%$ single pass removal efficiency for both coarse and fine particles. Interestingly, Irga et al. (2017) also compared biofilters with plants against those where the plants had been removed, leaving only the coconut husk plant growth substrate. This study found that the planted biofilters had greater PM removal efficiency than those with only substrate, indicating that the plants played a role in increasing filtration efficiency (Figure 11).

This idea was developed further by Pettit et al. (2017), who tested biofilters of the same type as used by Irga et al. (2017) but containing a range of different plant species. They found considerable differences in filtration efficiency amongst plant species, specifically that fern species, such as Nephrolepsis exalta bostoniensis ('Boston fern') produced active green 


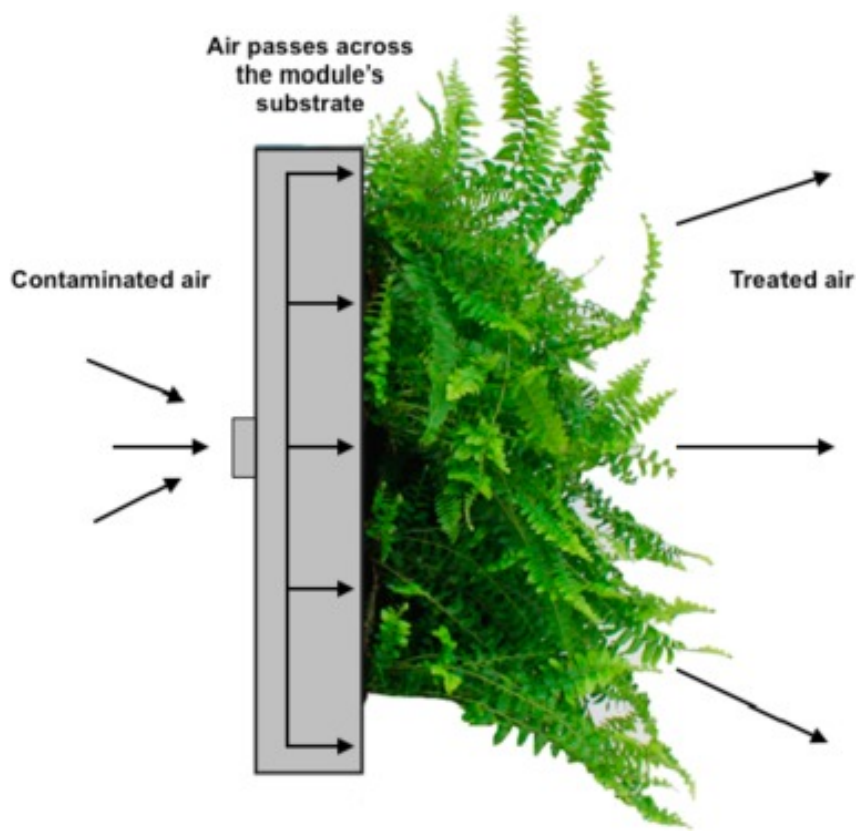

Figure 9. Breathing Wall active green wall system tested by Irga et al. (2017). Image reprinted from "Towards practical indoor air phytoremediation: A review”, by T. Pettit et al., 2018, Chemosphere, 208, pp. 960-974.

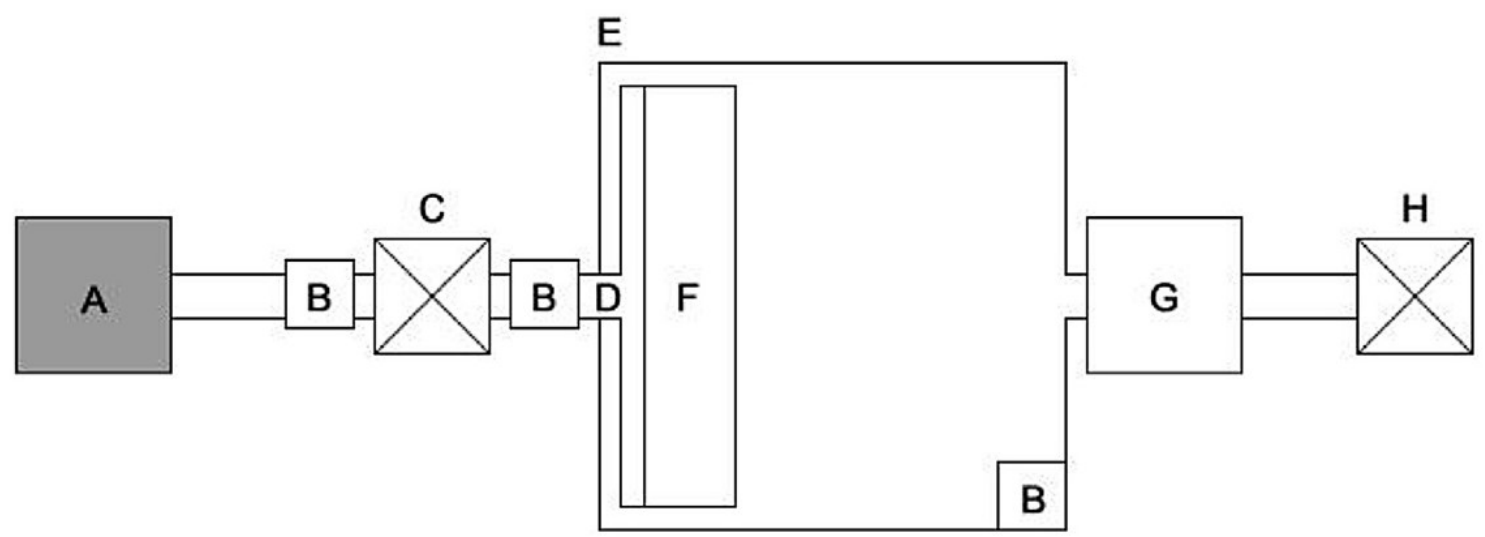

Figure 10. Schematic of the single pass efficiency test apparatus set up used by Irga et al. (2017): A: Combustion chamber; B: Digital pressure differential sensor; C: Ventilation fan; D: Plenum; E: Chamber; F: Biofilter substrate; G: PM measuring device; H: Exhaust vacuum pump. Reprinted from "An assessment of the atmospheric particle removal efficiency of an in-room botanical biofilter system”, by P.J. Irga et al., 2017, Building and Environment, 115, pp. 281-290.

walls with considerably higher PM filtration potential, including for ultra-fine particles (Figure 12). The proposed rationale for this observation was that the very fine root system possessed by these plant species forms a matrix that has a high affinity for the diesel smoke particulate stream tested. The system developed by Pettit et al. (2017) had greater filtration efficiency than the particulate filters commonly used in modern buildings, indicating that plant based systems have valuable potential for practical use.

For use in highly polluted environments, along with effective pollutant removal, biofilter plants will need to be capable of tolerating continuous exposure to high pollutant levels. Whilst differences in pollution tolerance between plant species in passive green walls (eg. Pandey et al., 2015), only the study by Paull et al. (2018) has comparatively trialled the 


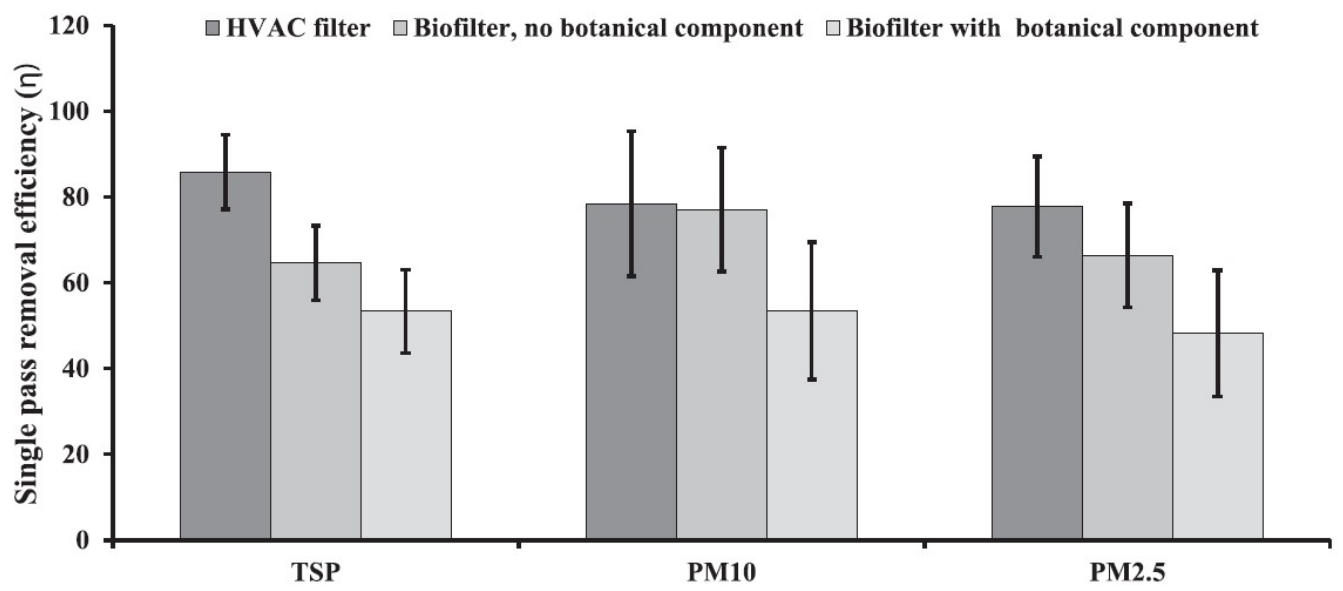

Figure 11. Single pass PM removal efficiencies of the active green wall system tested by Irga et al. (2017). TSP: total suspended particulates. Reprinted from "An assessment of the atmospheric particle removal efficiency of an in-room botanical biofilter system”, by P.J. Irga et al., 2017, Building and Environment, 115, pp. 281-290.

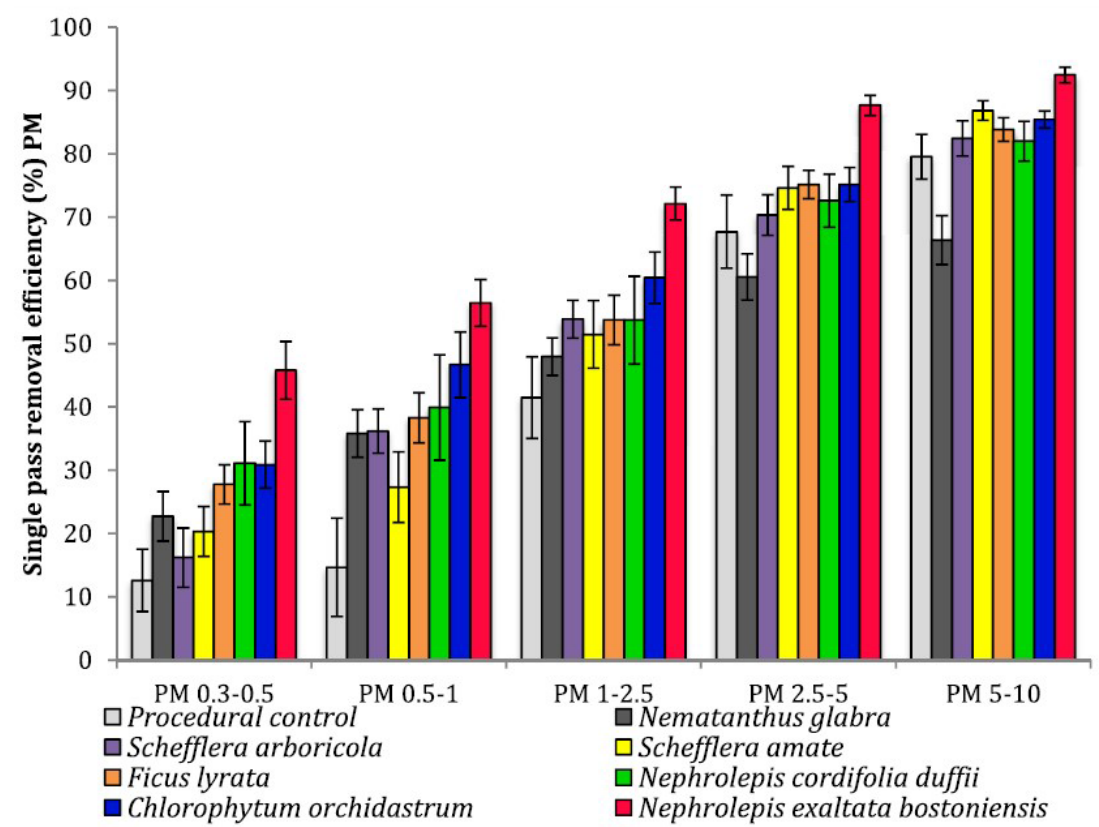

Figure 12. Average single pass removal efficiency (\%) for different active green wall plant species across independently sized PM fractions. Error bars represent standard error of the mean $(n=15)$. Reprinted from "Do the plants in functional green walls contribute to their ability to filter particulate matter?", by T. Pettit et al., 2017, Building and Environment, 125, pp. 299-307.

pollution tolerance of active green wall plants. These authors found that, as is the case for passive green wall plants (Pandey et al., 2015), fig species (Ficus spp.) were generally more tolerant than most other groups, although all species tested had reasonable tolerance, even to very high intensity pollution exposure. It is thus likely that a range of plants will be suitable for broad scale active green wall implementation, and it is probable that pollutant removal efficiency will have a greater importance in plant selection than tolerance to pollutants.

The type of substrate used in active green wall systems has also been the subject of some research. While Wang and Zhang's $(2011,2014)$ system showed that the addition of activated carbon can increase the VOC removal capacity of 
botanical biofilters, the study by Pettit et al. (2018a) demonstrated that the use of this additive may lead to reduced PM removal efficiency. This study also showed that substrate particle size (for coconut husk substrates) had variable effects on the removal of different types of VOCs, with medium-sized fractions producing the best general performance. Overall, substrate development for active botanical biofiltration systems designed for air pollutant removal is a poorly developed field (see Pettit et al., 2018b), and considerable further research will be required before the factors that contribute to VOC, $\mathrm{PM}$ and $\mathrm{CO}_{2}$ mitigation are fully resolved.

\section{Future directions}

Currently, active green wall technology is not widely used for air pollutant mitigation, despite the growing body of research showing highly promising potential. Whilst the major barrier to the uptake of this technology is most likely due to insufficient promotion of its benefits (eg. Torpy et al., 2015), there are valid criticisms of the testing that has been performed to date. Most research has been performed in small chambers, and the tested systems have not been adequately trialled on full scale buildings (Torpy et al., 2015; Soreanu, 2016). Most VOC research has used unrealistically high VOC concentrations, and there remains insufficient understanding of how botanical systems perform at real-world VOC levels in the parts per billion range (Torpy et al., 2018a). As stated previously, both plant species selection and substrate development are still at a nascent stage, and optimal system components have yet to be identified. The means by which active green wall air cleaning devices could be best integrated into existing building designs is also untested. A promising development application of botanical air filtration systems is their integration in building ventilation systems, where the normal air conditioning system ventilation fans force outdoor or recirculating indoor air though the biofilter before return to the indoor space. Wang and Zhang (2011) and Treesubsuntorn and Thiravetyan (2018) tested botanical biofilters of this type.

\section{Acknowledgements}

PJ Irga is supported by the UTS Chancellor's Postdoctoral Research Fellowship scheme and the Centre for Technology in Water and Wastewater (CTWW). T. Pettit is supported by an Australian Government Research Training Program Scholarship.

\section{References}

André, M. and P. Chagvardieff. 1997. CELSS research: interaction between space and terrestrial approaches in plant science. In: E. Goto, K. Kurata, M. Hayashi, and S. Sase (Eds.), Plant production in closed ecosystems(pp. 245-261): the international symposium on plant production in closed ecosystems held in Narita, Japan, August 26-29, 1996. Dordrecht, Netherlands: Springer.

Bakó-Biró, Z., P. Wargocki, C. J. Weschler, and P. O. Fanger. 2004. Effects of pollution from personal computers on perceived air quality, SBS symptoms and productivity in offices. Indoor Air 14:178-187.

Bari, M. A., M. MacNeill, W. B. Kindzierski, L. Wallace, M. E. Heroux, and A. J. Wheeler. 2014. Predictors of coarse particulate matter and associated endotoxin concentrations in residential environments. Atmos. Environ. 92:221-230. DOI:10.1016/j.atmosenv.2014.04.025

Bernstein, J. A., N. Alexis, H. Bacchus, I. L. Bernstein, P. Fritz, E. Horner, N. Li, S. Mason, A. Nel, J. Oullette, K. Reijula, T. Reponen, J. Seltzer, A. Smith, and S. M. Tarlo. 2008. The health effects of non-industrial indoor air pollution. J. Allergy Clin. Immunol. 121(3):585-591.

Buonanno, G., L. Morawska, and L. Stabile. 2009. Particle emission factors during cooking activities. Atmos. Environ. 


\section{3(20):3235-3242. DOI:10.1016/j.atmosenv.2009.03.044}

Burroughs, H. and S. J. Hansen. 2004. Managing indoor air quality. CRC Press.

Colbeck, I. and Z. A. Nasir. 2010. Indoor air pollution. In: M. Lazaridis and I. Colbeck (Eds.), Human exposure to pollutants via dermal absorption and inhalation(pp. 41-72). Netherlands: Springer.

Darlington, A., J. Dat, and M. Dixon. 2001. The biofiltration of indoor air: Air flux and temperature influences the removal of toluene, ethylbenzene, and xylene. Environ. Sci. Technol. 35(1):240-246. DOI:10.1021/es0010507

Delhoménie, M. C. and M. Heitz. 2003. Elimination of chlorobenzene vapors from air in a compost-based biofilter. J. Chem. Technol. Biotechnol. 78(5):588-595. DOI:10.1002/jctb.822

Erdmann, C. A. and M. G. Apte. 2004. Mucous membrane and lower respiratory building related symptoms in relation to indoor carbon dioxide concentrations in the 100-building BASE dataset. Indoor Air. 14(Suppl 8):127-134.

Fiedler, N., R. Laumbach, K. Kelly-McNeil, P. Lioy, Z. H. Fan, J. Zhang, J. Ottenweller, P. Ohman-Strickland, and H. Kipen. 2005. Health effects of a mixture of indoor air volatile organics, their ozone oxidation products, and stress. Environ. Health Perspect. 113(11):1542-1548.

Grayston, S. J. and C. E. Prescott. 2005. Microbial communities in forest floors under four tree species in coastal British Columbia. Soil Biol. Biochem. 37(6): 1157-1167. DOI: 10.1016/j.soilbio.2004.11.014

Hutton, G. 2013. Air pollution: global damage costs from 1900 to 2050. In: B. Lomborg (Ed.), How much have global problems cost the world? A scorecard from 1900 to 2050(pp. 70-98). New York, USA: Cambridge University Press.

Irga, P. J., F. R. Torpy, and M. D. Burchett. 2013 Can hydroculture be used to enhance the performance of indoor plants for the removal of air pollutants? Atmos. Environ. 77:267-271.

Irga, P. J., N. J. Paull, P. Abdo, and F. R. Torpy. 2017. An assessment of the atmospheric particle removal efficiency of an in-room botanical biofilter system. Build. Environ. 115:281-290. DOI: 10.1016/j.buildenv.2017.01.035

Jaakola, M., L. Yang, A. Ieromnimon, and J. Jaakola. 2007. Office work exposures and respiratory and sick building syndrome symptoms. Occup. Environ. Med. 64(3):178-184. DOI; 10.1136/oem.2005.024596

Jafari, M.J., A. A. Khajevandi, S. A. M. Najarkola, M. S. Yekaninejad, M. A. Pourhoseingholi, L. Omidi, and S. Kalantary. 2015. Association of sick building syndrome with indoor air parameters. Tanaffos 14(1):55-62.

Kim, K. J., M. I. Jeong, D. W. Lee, J. S. Song, H. D. Kim, E. H. Yoo, S. J. Jeong, S. W. Han, S. J. Kays, Y. W. Lim, and H. H. Kim. 2010. Variation in formaldehyde removal efficiency among indoor plant species. HortScience 45(10):1489-1495.

Kim, K. J., M. Khalekuzzaman, J. N. Suh, H. J. Kim, C. Shagol, H. H. Kim, and H. J. Kim. 2018. Phytoremediation of volatile organic compounds by indoor plants: a review. Hortic. Environ. Biotechnol. 59(2):143-157. DOI:10.1007/s13580-018-0032-0

Kim, K. J., M. J. Kil, J. S. Song, E.H. Yoo, K. C. Son, and S. J. Kays. 2008. Efficiency of volatile formaldehyde removal by indoor plants: Contribution of aerial plant parts versus the root-zone. J. Am. Soc. Hortic. Sci. 133(4):521-526.

Klepeis, N. E., W.C. Nelson, W. R. Ott, J. P. Robinson, A. M. Tsang, P. Switzer, J. V. Behar, S.C. Hern, and W. H. Engelmann. 2001. The National Human Activity Pattern Survey (NHAPS): a resource for assessing exposure to environmental pollutants. J. Expo. Sci. Environ. Epidemiol. 11(3):231-252. DOI:10.1038/sj.jea.7500165

Lee, C. H., B. Choi, and M. Y. Chun. 2015. Stabilization of soil moisture and improvement of indoor air quality by a plant-biofilter integration system. Korean J. Hortic. Sci. Technol. 33(5):751-762.

Llewellyn, D. and M. Dixon. 2011. Can plants really improve indoor air quality? In: M. Moo-Young (Ed.), Comprehensive biotechnology(2nd ed., pp. 331-338). Burlington: Academic Press.

Maji, K. J., A. K. Dikshit, and A. Deshpande. 2017. Disability-adjusted life years and economic cost assessment of the health effects related to PM2.5 and PM10 pollution in Mumbai and Delhi, in India from 1991 to 2015. Environ. Sci. Pollut. Res. 24(5):4709-4730.

Milton, D. K., P. M. Glencross, and M. D. Walters. 2000. Risk of sick leave associated with outdoor air supply rate, humidification, and occupant complaints. Indoor Air 10(4):212-221.

Molloy, S. B., M. Cheng, I. E. Galbally, M. D. Keywood, S. J. Lawson, J. C. Powell, R. Gillett, E. Dunne, and P. W. 
Selleck. 2012. Indoor air quality in typical temperate zone Australian dwellings. Atmospheric environment. 54:400-407. DOI:10.1016/j.atmosenv.2012.02.031

Morawska, L., C. He, J. Hitchins, K. Mengersen, and D. Gilbert. 2003. Characteristics of particle number and mass concentrations in residential houses in Brisbane, Australia. Atmos. Environ. 37(30):4195-4203.

DOI:10.1016/S1352-2310(03)00566-1

Pandey, A. K., M. Pandey, A. Mishra, S. M. Tiwary, and B. D. Tripathi. 2015. Air pollution tolerance index and anticipated performance index of some plant species for development of urban forest. Urban For. Urban Green. 14(4):866-871. DOI:10.1016/j.ufug.2015.08.001

Paull, N. J., P. J. Irga, and F. R. Torpy. 2018. Active green wall plant health tolerance to diesel smoke exposure. Environ. Pollut. 240:448-456. DOI:10.1016/j.envpol.2018.05.004

Pettit, T., P. J. Irga, and F. R. Torpy. 2018a. Functional green wall development for increasing air pollutant phytoremediation: Substrate development with coconut coir and activated carbon. J. Hazard. Mater. 360:594-603. DOI:10.1016/j.jhazmat.2018.08.048

Pettit, T., P. J. Irga, and F. R. Torpy. 2018b. Towards practical indoor air phytoremediation: A review. Chemosphere 208:960-974. DOI:10.1016/j.chemosphere.2018.06.048

Pettit, T., P. J. Irga, P. Abdo, and F. R. Torpy. 2017. Do the plants in functional green walls contribute to their ability to filter particulate matter? Build. Environ. 125:299-307. DOI: 10.1016/j.buildenv.2017.09.004

Quang, T. N., C. He, L. Morawska, and L. D. Knibbs. 2013. Influence of ventilation and filtration on indoor particle concentrations in urban office buildings. Atmos. Environ. 79:41-52. DOI:10.1016/j.atmosenv.2013.06.009

Redlich, C., J. Sparer, and M. Cullen. 1997. Sick-building syndrome. Lancet. 349(9057):1013-1016. DOI:10.1016/S0140-6736(96)07220-0

Riley, W. J., T. E. McKone, A. C. K. Lai, and W. W. Nazaroff. 2002. Indoor particulate matter of outdoor origin: Importance of size-dependent removal mechanisms. Environ. Sci. Technol. 36(2):200-207. DOI:10.1021/es010723y

Rohr, A. C. and R. E. Wyzga. 2012. Attributing health effects to individual particulate matter constituents. Atmos. Environ. 62:130-152. DOI:10.1016/j.atmosenv.2012.07.036

Salisbury, F. B., J. I. Gitelson, and G. M. Lisovsky. 1997. Bios-3: Siberian experiments in bioregenerative life support: Attempts to purify air and grow food for space exploration in a sealed environment began in 1972. BioScience 47(9):575-585. DOI:10.2307/1313164

Sæbø, A., R. Popek, B. Nawrot, H. M. Hanslin, H. Gawronska, and S. W. Gawronski. 2012. Plant species differences in particulate matter accumulation on leaf surfaces. Sci. Total Environ. 427-428(0):347-354. DOI:10.1016/j.scitotenv.2012.03.084

Seppänen, O. A. and W. J. Fisk. 2004. Summary of human responses to ventilation. Indoor Air 14(Suppl 7):102-118.

Seppänen, O., W. J. Fisk, and Q. H. Lei. 2006. Ventilation and performance in office work. Indoor Air 16(1):28-36.

Shaughnessy, R. J., U. Haverinen-Shaughnessy, A. Nevalainen, and D. Moschandreas. 2006. A preliminary study on the association between ventilation rates in classrooms and student performance. Indoor Air 16(6):465-468.

Soreanu, G. 2016. Biotechnologies for improving indoor air quality. In: Start-up creation (pp. 301-328). The Smart Eco-Efficient Built Environment. DOI:10.1016/B978-0-08-100546-0.00012-1

Stapleton, E. and P. Ruiz-Rudolph. 2016. The potential for indoor ultrafine particle reduction using vegetation under laboratory conditions. Indoor Built Environ. 27(1):70-83.

$\mathrm{Su}$, Y. and Y. Liang. 2015. Foliar uptake and translocation of formaldehyde with Bracket plants (Chlorophytum comosum). J. Hazard. Mater. 291:120-128. DOI:10.1016/j.jhazmat.2015.03.001

Torpy, F., N. Clements, M. Pollinger, A. Dengel, I. Mulvihill, C. He, and P. Irga. 2018a. Testing the single-pass VOC removal efficiency of an active green wall using methyl ethyl ketone (MEK). Air Qual. Atmos. Health 11(2):163-170. DOI:10.1007/s11869-017-0518-4

Torpy, F. and M. Zavattarro. 2018b. Bench-study of green-wall plants for indoor air pollution reduction. J. Living Archit. 5(1):1-15. 
Torpy, F. R., M. Zavattaro, and P. J. Irga. 2017. Green wall technology for the phytoremediation of indoor air: a system for the reduction of high CO2 concentrations. Air Qual. Atmos. Health 10(5):575-585.

Torpy, F. R., P. J. Irga, D. Moldovan, J. Tarran, M.D. Burchett. 2013. Characterization and biostimulation of benzene biodegradation in the potting-mix of indoor plants. J. Appl. Hortic. 15(1):10-15.

Torpy, F. R., P. J. Irga, and M. D. Burchett. 2014. Profiling indoor plants for the amelioration of high CO2 concentrations. Urban For. Urban Green. 13(2):227-233. DOI:10.1016/j.ufug.2013.12.004

Torpy, F. R., P. J. Irga, and M. D. Burchett. 2015. Reducing indoor air pollutants through biotechnology. In: F. Pacheco Torgal, J. Labirncha, M. Diamanti, C.P. Yu, and H. Lee(Eds.), Biotechnologies and Biomimetics for Civil Engineering(pp. 181-210). Springer International Publishing.

Treesubsuntorn, C. and P. Thiravetyan. 2018. Botanical biofilter for indoor toluene removal and reduction of carbon dioxide emission under low light intensity by using mixed C3 and CAM plants. J. Clean. Prod. 194:94-100. DOI:10.1016/j.jclepro.2018.05.141

Tunno, B. J., K. N. Shields, L. Cambal, S. Tripathy, F. Holguin, P. Lioy, and J. E. Clougherty. 2015. Indoor air sampling for fine particulate matter and black carbon in industrial communities in Pittsburgh. Sci. Total Environ. 536:108-115.

Vaughan, T. L., C. Strader, S. Davis, and J. R. Daling. 1986. Formaldehyde and cancers of the pharynx, sinus and nasal cavity: II. Residential exposures. Int. J. Cancer 38(5):685-688.

Wallace, L. A. 2001. Human exposure to volatile organic pollutants: implications for indoor air studies. Annu. Rev. Energy Environ. 26:269-301. DOI:10.1146/annurev.energy.26.1.269

Wang, Z., J. Pei, and J. S. Zhang. 2014. Experimental investigation of the formaldehyde removal mechanisms in a dynamic botanical filtration system for indoor air purification. J. Hazard. Mater. 280:235-243. DOI:10.1016/j.jhazmat.2014.07.059

Wang, Z. and J .S. Zhang. 2011. Characterization and performance evaluation of a full-scale activated carbon-based dynamic botanical air filtration system for improving indoor air quality. Build. Environ. 46(3):758-768. DOI:10.1016/j.buildenv.2010.10.008

Waring, M. S. 2016, October. Bio-walls and indoor houseplants: Facts and fictions. In: Microbiomes of the Built Environment: From Research to Application, Meeting \#3. University of California, Irvine.

Weerakkody, U., J. W. Dover, P. Mitchell, and K. Reiling. 2017. Particulate matter pollution capture by leaves of seventeen living wall species with special reference to rail-traffic at a metropolitan station. Urban For. Urban Green. 27:173-186. DOI:10.1016/j.ufug.2017.07.005

Weschler, C. J. 2009. Changes in indoor pollutants since the 1950s. Atmos. Environ. 43(1):153-169. DOI:10.1016/j.atmo senv.2008.09.044

Wheeler, R., C. Mackowiak, G. Stutte, J. Sager, N. Yorio, L. Ruffe, R. Fortson, T. Dreschel, W. Knott, and K. Corey. 1996. NASA's biomass production chamber: a testbed for bioregenerative life support studies. Adv. Space Res. 18(4-5):215-224.

Wolkoff, P. 2013. Indoor air pollutants in office environments: assessment of comfort, health, and performance. Int. J. Hyg. Environ. Health 216(4):371-394. DOI:10.1016/j.ijheh.2012.08.001

Wolverton, B. C., A. Johnson, and K. Bounds. 1989. A study of interior landscape plants for indoor air pollution abatement (NASA-TM-108061). Stennis Space Center, MS: National Aeronautics and Space Administration.

Wolverton, B. C. and J. D. Wolverton. 1993. Plants and soil microorganisms: removal of formaldehyde, xylene, and ammonia from the indoor environment. J. Miss. Acad. Sci. 38(2):11-15.

Wolverton, B., R. C. McDonald, and E. Watkins. 1984. Foliage plants for removing indoor air pollutants from energy-efficient homes. Economic Botany. 38(2):224-228.

Wood, R. A., M. D. Burchett, A. Alquezar, R. Orwell, J. Tarran, and F. Torpy. 2006. The potted-plant microcosm substantially reduces indoor air VOC pollution: I. Office field-study. Water Air Soil Pollut. 175(1):163-180. DOI:10.1007/s11270-006-9124-Z

Wood, R. A., R. L. Orwell, J. Tarran, F. Torpy, and M. Burchett. 2002. Potted-plant/growth media interactions and capacities in removal of volatiles from indoor air. J. Hortic. Sci. Biotechnol. 77(1):120-129.

DOI:10.1080/14620316.2002.11511467 
World Health Organization. 2010. WHO guidelines for indoor air quality: selected pollutants. Geneva, Switzerland: WHO Press.

World Health Organization. 2016. Global report on urban health: equitable, healthier cities for sustainable development. Geneva, Switzerland: WHO Press.

Wyzga, R. E. and A. C. Rohr. 2015. Long-term particulate matter exposure: Attributing health effects to individual PM components. J. Air Waste Manag. Assoc. 65(5):523-543. DOI:10.1080/10962247.2015.1020396

Xing, Y. F., Y. H. Xu, M. H. Shi, and Y. X. Lian. 2016. The impact of PM2.5 on the human respiratory system. J. Thorac. Dis. 8(1):E69-E74. DOI:10.3978/j.issn.2072-1439.2016.01.19 